\title{
Sensitivity and uncertainty analysis on water quality modelling of Aguamilpa reservoir
}

\author{
Jesús G. RANGEL-PERAZA, ${ }^{1 *}$ José DE ANDA, ${ }^{2}$ Fernando A. GONZÁLEZ-FARÍAS, ${ }^{3}$ Michael RODE ${ }^{4}$ \\ ${ }^{1}$ División de Estudios de Posgrado e Investigación - Ingeniería Ambiental, Instituto Tecnológico de Culiacán, Juan de Dios Batiz 310 , \\ Col. Guadalupe, 80220 Culiacán, Sinaloa, México; ${ }^{2}$ Unidad de Tecnología Ambiental, Centro de Investigación y Asistencia en \\ Tecnología y Diseño del Estado de Jalisco, Av. Normalistas 800, Col. Colinas de la Normal, 44270 Guadalajara, Jalisco, México; \\ ${ }^{3}$ Instituto de Ciencias del Mar y Limnología, Universidad Nacional Autónoma de México, Ciudad Universitaria, 04510 México, DF; \\ ${ }^{4}$ Helmholtz-Zentrum fur Umweltforschung, Bruckstrasse 3a, 39114 Magdeburg, Germany \\ *Corresponding author: jesus.rangel@itculiacan.edu.mx
}

\begin{abstract}
The use of water quality models is determined to a great extent by their ability to accurately reproduce observed data series and by their predictive capability without the need to adjust the calibrated parameters. However, the observed abiotic variables involved in a system are measured with a level of uncertainty. The sensitivity analysis concepts and generalized methodology of uncertainty analysis were used via a computer tool called UNCSIM. As a first step, a parametric optimization model of the Aguamilpa reservoir water quality was accomplished. The aforementioned analysis identified that the wind sheltering coefficient (WSC), Chezy bottom friction solution (FRICC), and coefficient of bottom heat exchange (CBHE) were the parameters of the CE-QUAL-W2 model that significantly influenced the behavior of temperature and dissolved oxygen concentration in the reservoir. Afterwards, the uncertainty of the water quality model was evaluated through the modification of the hydrological and climatological information, which had a major influence on the simulation of the system. This analysis showed the possible changes in hydrodynamic and water quality characteristics of the reservoir, including an increase in the thermocline due to a possible air temperature increase and a rainfall decrease in the region. The innovative coupling routine of the different modules for the sensitivity and uncertainty analysis developed in this research establishes the basis for the future development of a modelling platform to conduct water quality simulations of the Aguamilpa reservoir in real time through continuous meteorological and water discharge information.
\end{abstract}

Key words: Sensitivity and uncertainty analysis; water quality modelling; CE-QUAL-W2; Aguamilpa reservoir; Mexico.

Received: February 2015. Accepted: November 2015.

\section{INTRODUCTION}

In the last decades, climate change has had an impact on the natural and human systems in all continents and along the oceans. The climate change impact evidence is important and is being widely studied in several natural systems and in different regions of the planet. The oceans and the environment have shown an increase in their average global temperature, the melting of ice and snow, and the mean sea level (IPCC, 2014).

The global warming observed in the last 50 years is more likely greater than any other similar period in the last 1300 years. The global temperature has increased by $0.74^{\circ} \mathrm{C}$ over the last 100 years, and the warming tendency of the last 50 years is an increase of $0.13^{\circ} \mathrm{C}$ for each decade (Gay et al., 2008). Accordingly, a great number of long-term changes in the climate have been registered. These changes include increases in the intensity of tropical storms, in heat waves, and in the frequency and intensity of some extreme events, such as droughts and torrential rains. A significant increase has been observed in temperate latitude precipitation; however, in tropical and subtropical regions, longer and more intense droughts have been registered since 1970. As a consequence of these changes, the IPCC (2014) has suggested that many hydrological systems are affected, including the warming of lakes and rivers in many regions, which affects the thermic structure and water quality and modifies the composition and abundance of aquatic species.

Some developing countries have made efforts to adapt to such changes by implementing strategies with a particular focus on ecosystem conservation, via the development of an early warning system. However, the effectiveness of those efforts has been overtaken by a lack of basic information, the lack of a basic monitoring programme or permanent observation systems, irregular human settlement in vulnerable zones, and a lack of governmental politics and proper technical strategies. The observed changes and future scenarios are the fundamental motivation for proposing new modelling studies for natural water bodies located in developing countries, including those within tropical regions, particularly Mexico. To predict the impacts under different foreseen scenarios more accurately, 
it is necessary to include the natural climate variability and the contributions of human activities to global climate change. The value of water quality models is determined, to a great extent, by their ability to accurately reproduce observed data series and by their capability to forecast other time series without needing adjustments to the calibrated parameters. However, the hydrologic and climatological variables needed for their development are observed measurements that involve uncertainty due to the high variability of the system components. This effect spreads through the utilization of such variables in the model equations. Hence, it is necessary to employ techniques to quantify the existing uncertainty in the model parameters and in the data used in the selected water quality model, with the purpose of determining the predictive capability of the model (Rode et al., 2010).

The main goal of this work is to determine the dominant processes and parameters in the water quality model developed for the Aguamilpa reservoir. The strategy will be to use parametric sensitivity analysis and to evaluate the existing uncertainty of the model through climatological and hydrological data series analysis using the water quality information measured in the frontiers of the system.

\section{METHODS}

\section{Study area}

The Aguamilpa reservoir is located in the central region of the state of Nayarit, Mexico and covers parts of the municipalities of Nayar, La Yesca, Santa Maria del Oro and Tepic. The Aguamilpa concrete-faced rockfill dam, which is $187 \mathrm{~m} \mathrm{high,} \mathrm{is} \mathrm{one} \mathrm{of} \mathrm{the} \mathrm{highest} \mathrm{of} \mathrm{its} \mathrm{type}$ in the world (de Anda et al., 2012). The main water contributions to the reservoir come from the Santiago and Huaynamota rivers. The reservoir is approximately $60 \mathrm{~km}$ long, following the Santiago river course and $20 \mathrm{~km}$ along the Huaynamota River, covering a $109 \mathrm{~km}^{2}$ area (Fig. 1).

\section{Water quality model development}

\section{Selection}

The Aguamilpa reservoir has an elongated and narrow shape, with a bathymetric profile typical of dams that are built for power generation. This reservoir shows a longitudinal and vertical variation in its biological and physicochemical characteristics (Rangel-Peraza et al., 2009). As a consequence of these features, CE-QUAL-W2 was selected as the best model to simulate the water quantity and water quality of the reservoir. CE-QUAL-W2 is one of the best known and most used modules worldwide for water quality simulations of reservoirs. Therefore, the results obtained using this model could be compared with those obtained for other reservoirs with the same simulation module.

\section{Governing equations}

CE-QUAL-W2 allows the two-dimensional modelling of narrow and deep dams, as is the case for the Aguamilpa reservoir. It is also possible to simulate the physical, chemical, and biological characteristics of a water body in vertical and longitudinal dimensions under dynamic conditions. The model is based on solving the two-dimensional, unsteady, hydrodynamic and advective-diffusion equations, as shown in Tab. 1 (Cole and Wells, 2005).

Tab. 1. CE-QUAL-W2 Governing equations.

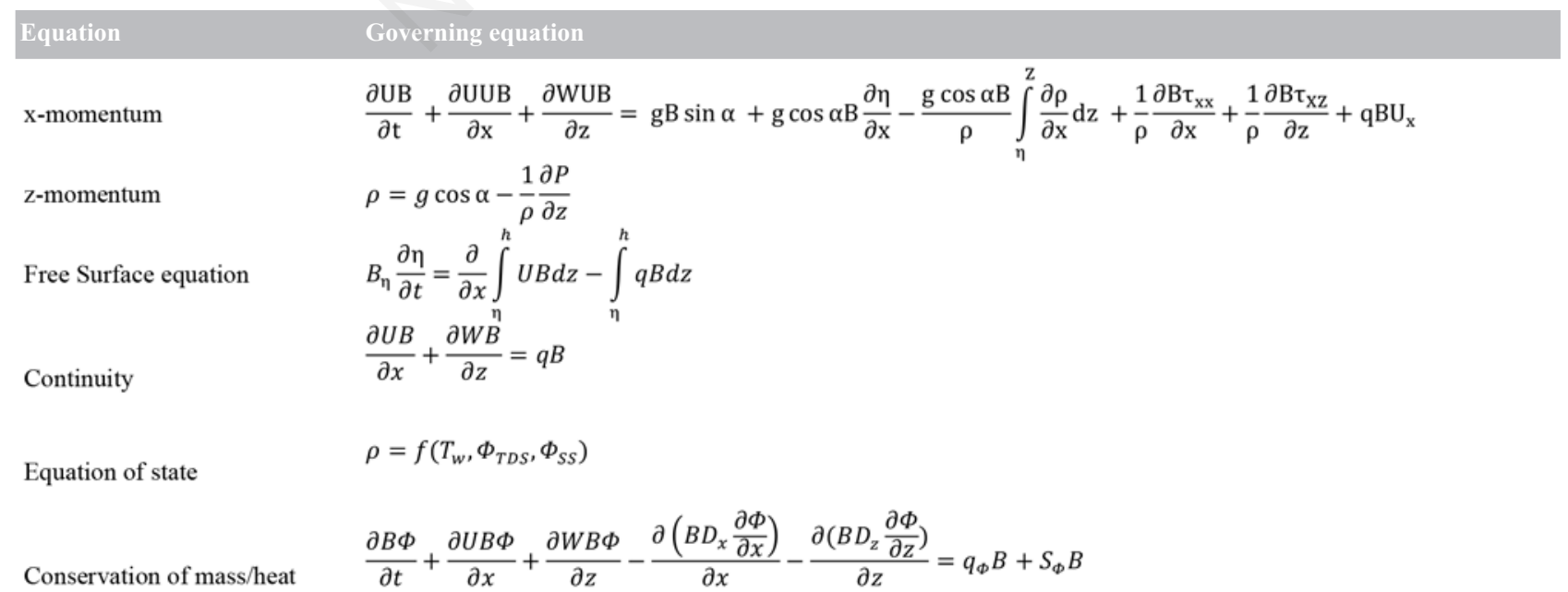

$B$ is the width, $U$ is the longitudinal velocity, $W$ is the vertical velocity, $q$ is the inflow per unit width, $\alpha$ is the channel angle, $\Phi$ is the concentration or temperature, $\eta$ is the water surface elevation, $P$ is the pressure, $h$ is the depth, $T_{W}$ is the water temperature, $\Phi_{T D S}$ is the concentration of TDS, $\Phi_{S S}$ is the concentration of suspended solids, and $\rho$ is the density. 


\section{Geometry}

The Aguamilpa reservoir system delineation was created with the Watershed Modeling System (WMS) version 8.0 (Aquaveo, 2010) by processing Digital Elevation Models (DEMs) obtained from INEGI (2011). The resulting system geometry matched up well with the Aguamilpa hypsographic curves provided by the Federal Electricity Commission (CFE, 1991). Then, the bathymetry was discretized into 103 longitudinal segments along the three tributary branches. Each segment was further sub-divided into 178 vertical layers of $1 \mathrm{~m}$ thick.

\section{Boundary conditions}

Water inflows, outflows and lake surface elevations were obtained from a water balance carried out in the Aguamilpa reservoir based on the methodology established by Rangel-Peraza and Ortiz-Jimenez (2012). Hourly meteorological data, including air temperature, percent relative humidity, wind speed, wind direction and total incident solar radiation, were gathered from the weather monitoring station located close to the Aguamilpa dam wall, which was operated by the National Water Commission (CONAGUA, 2008).

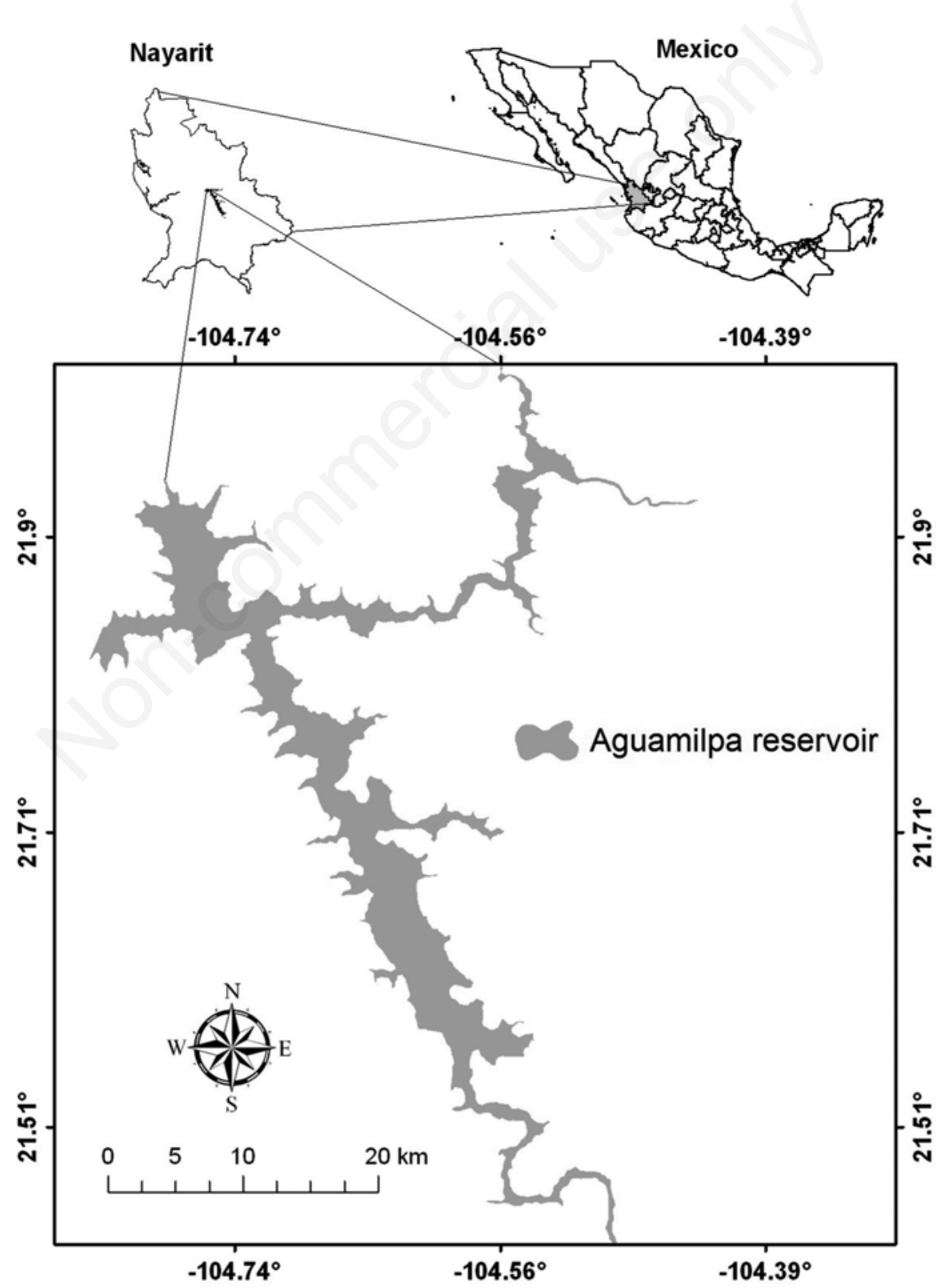

Fig. 1. Geographic location of Aguamilpa reservoir. 


\section{Calibration}

A real-time gauging station located near Aguamilpa Dam, operated by the Federal Electricity Commission (CFE), was used to monitor the daily precipitation, evaporation, water releases and reservoir water levels. Hourly intake water volumes were obtained from the operation records of El Cajon Reservoir, a reservoir located upstream on the Santiago River. The reservoir water balance was calibrated using these data. Water balance calibration was carried out by solving for the unaccounted flows (runoff, direct precipitation over the reservoir surface, subsurface springs) observed during the study period.

A water quality probe (YSI Model6600D) was used once every other month to monitor water temperature, dissolved oxygen and total dissolved solid concentration profiles at eight sampling sites in the reservoir from June 2007 to June 2008. The model was calibrated using the field-collected data. Model performance was previously evaluated by Rangel-Peraza et al. (2012).

\section{Systematic analysis of the water quality model}

To improve the prediction capability of the used water quality model, the statistical software known as UNCSIM was used (Reichert, 2004). This software provides a technique to implement the most important steps for data analysis calculated with a mathematical model. This technique includes statistical inference, sensitivity and uncertainty analysis (Omlin et al., 2000; Lindenschmidt, 2006).

CE-QUAL-W2 is a complex model that consists of over 23 parameters related to hydrodynamic and water quality characteristics (Cole and Wells, 2005). The high number of model parameters makes it difficult to evaluate both the uniqueness of the parameter values used and the reliability of the results obtained from the simulation. The use of the statistical tool UNCISM was appropriate to solve this situation through sensitivity analysis. Sensitivity analysis consists of tuning the model parameters and then optimizing the simulation water quality values obtained based on the observed variables.

To use this statistical tool, a simple interface was developed between the water quality model CE-QUAL-W2 and the UNCSIM software. This interface has been developed in other water quality models: AQUASIM, a program used for the simulation of aquatic systems and data analysis (Reichert, 1994); the Soil and Water Assessment Tool (SWAT), a program used for hydrological simulation and water quality assessment at the basin level (Arnold et al., 1998); and LEACHM, an implementation of a deterministic model used to measure the dynamic of nitrogen in soil (Hutson and Wagenet, 1991). The basic idea underlying the development of an interface between UNCSIM and CE-QUAL-W2 is shown in Fig. 2.

UNCSIM calculates the possible climatological and hydrologic scenarios and saves the results of this simulation in a file under the name model.in. Then, an executable file called $W 2$ edit.exe modifies the control file in which the main parameters of the water quality model are determined and writes these new inputs, together with the climatological and hydrologic conditions, in the required format of the CE-QUAL-W2 model. This information is read and validated for this model, and after validation, the model begins the next simulation. The $W 2$ extract.exe file writes the results of the water quality mathematical simulation in a different file called model.out. This last file can be read directly by the statistic tool UNCSIM, creating a routine that will end once 500 simulations have been performed. According to Railsback and Grimm (2012), 500 replications are sufficient to obtain stable results (no multicollinearity among factors) and a high accuracy simulation (small integration errors). The executable programs are written in the high level programming language Java (Oracle, 2013) using the platform to develop apps in an integrated development environment called Netbeans IDE 7.1.4. These programs have been developed with the objective of modifying the input files. Then, the simulated information can be directly called to CE-QUAL-W2. The aforementioned procedure is known as the system analysis routine (Reichert, 1994), and it is executed with the goal of avoiding the modification of the water quality model input files that normally occurs when performed by hand.

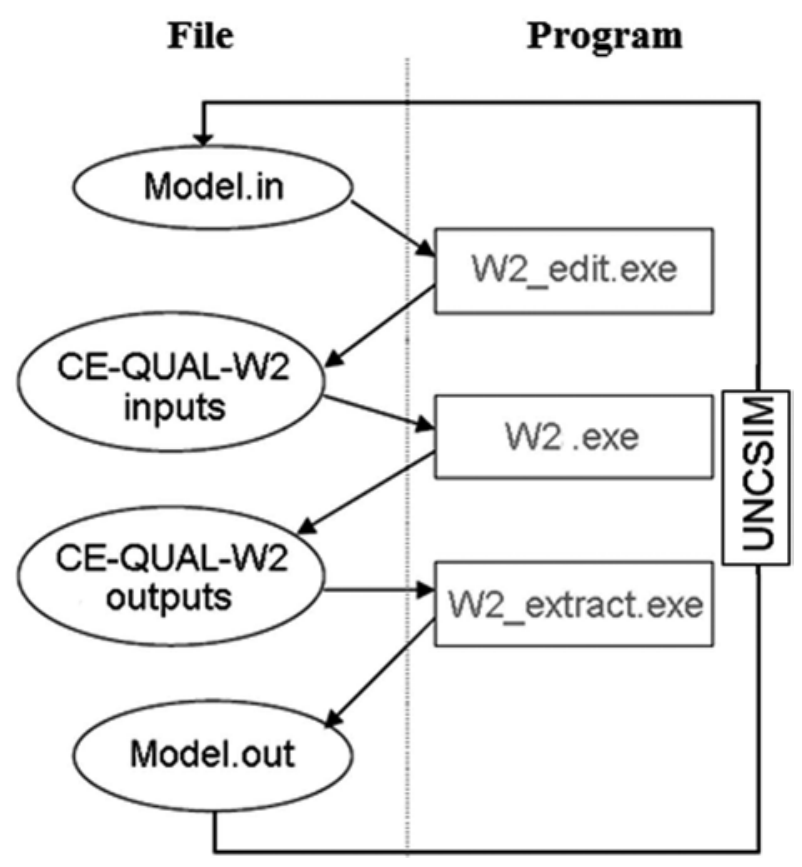

Fig. 2. Diagram that shows the cyclical sequence operation of the communication interface developed between CE-QUAL-W2 and UNCSIM. 


\section{Sensitivity analysis}

Once the interface between UNCSIM and CE-QUALW2 was developed, an analysis of the principal parameters that influence the thermic structure and water quality behavior of the Aguamilpa reservoir was carried out via a sensitivity analysis. The objective of sensitivity analysis is to determine which parameters of the governing equations affect the output variables and to quantify the error that can be led to the simulation results (Afshar and Saadatpour, 2009).

The sensitivity analysis for the Aguamilpa water quality model was conducted using the traditional grid perturbation method (Caers and Hoffman, 2006), which consisted of fluctuating each of the defined parameters in Tab. 2. These parameters were recognized as the most important of the water quality model during the validation and calibration process (Rangel-Peraza et al., 2012). The calibration parameter values decreased and increased within a defined percentage $(+/-50 \%$ and $+/-20 \%$ for all parameters, respectively). The output deviations of temperature, dissolved oxygen, and total dissolved solids reflect the response sensitivity, which represents the differences produced in each experiment and defines the parameters of the model that have greater influence.

The water quality model sensitivity was calculated using a sensitivity coefficient (SC). This arises from the quotient divided by the change percentage in the model output variable with respect to the change percentage in the input variable (modified parameter), as shown in Eq. 1.

$S C=\frac{(\% \text { change in the output variables })}{(\% \text { change in the input parameters })}$

\section{Uncertainty analysis}

Once the most representative parameters were identified, model uncertainty propagation was carried out with the goal of understanding the influence of the external factors, such as air temperature and water balance, on the model output variables. The uncertainty was evaluated through the modification of the hydrological and climatological input data that have a major influence on the water quality simulation. There is no unique method for the generation of climatological and hydrological scenarios. Different approaches can be observed in the national communications that countries have delivered to the United Nations Framework Convention. The approaches highly depend on the scientific and technical capability of each country (IPCC, 2014). The most advanced resource available for the generation of climatological scenarios is the set denoted as General Circulation Models (GCM's) (IPCC, 2014). These models simulate a variety of processes that happen over a wide interval of spatial and temporary scales among the diverse climatic subsystems. The variables that get more attention because of their indisputable importance are air temperature and precipitation. Nevertheless, significant changes have been widely observed in climatic factors on a regional scale due to the presence of sea surface temperature anomalies related to El Niño/southern Oscillation (ENSO) events (Lienert and Doblas-Reyes, 2013). The atmospheric response to sea surface temperature anomalies is difficult to detect using GCMs. Therefore, it is necessary to apply regionalization techniques to use the information given by the GCMs.

An innovative methodology is applied to generate Aguamilpa climate scenarios. This methodology is based on the fact that weather predictions can only be given in a probabilistic manner, which reflects the random nature of climatic systems. Therefore, a weather forecast must be performed with several numeric experiments that start with slightly different initial conditions. The whole set of experiments constitutes an assembly, establishing the most probable condition. The variation among these experiments determines a confidence level (uncertainty) and could be expressed as a Probability Density Function (PDF) (Coleman and Steele, 2009). In this way, the gathered information not only includes the mean value but

Tab. 2. Selected parameters of the water quality calibrated model for temperature sensitivity analysis and the confidence interval of the values.

\begin{tabular}{lcccccccc} 
Description & Variable & Unit & $-50 \%$ & $-20 \%$ & Calibration value & $20 \%$ & $50 \%$ \\
Longitudinal eddy viscosity & $\mathrm{AX}$ & $\mathrm{m}^{2} \mathrm{~s}^{-1}$ & 0.5 & 0.8 & 1.0 & 1.2 & 1.5 \\
Longitudinal eddy diffusivity & $\mathrm{DX}$ & $\mathrm{m}^{2} \mathrm{~s}^{-1}$ & 0.5 & 0.8 & 1.0 & 1.2 & 1.5 \\
\hline Chezy bottom friction solution & FRICC & $\mathrm{m}^{1 / 2} \mathrm{~s}^{-1}$ & 35 & 56 & 70 & 84 & 105 \\
Wind sheltering coefficient & $\mathrm{WSC}$ & - & 0.72 & 1.16 & 1.45 & 1.74 & 2.17 \\
\hline Fraction of incident solar radiation absorbed at the water surface & $\mathrm{BETA}$ & - & 0.21 & 0.33 & 0.42 & 0.50 & 0.63 \\
Light extinction coefficient for pure water & EXH2O & $\mathrm{m}^{-1}$ & 0.25 & 0.4 & 0.5 & 0.6 & 0.75 \\
\hline Coefficient of bottom heat exchange & $\mathrm{CBHE}$ & $\mathrm{W} \mathrm{m} \mathrm{m}^{-2}{ }^{\circ} \mathrm{C}^{-1}$ & 0.15 & 0.24 & 0.3 & 0.36 & 0.45 \\
Input water temperature & & ${ }^{\circ} \mathrm{C}$ & $0.5 \mathrm{~T}_{\mathrm{w}}$ & $0.8 \mathrm{~T}_{\mathrm{w}}$ & $\mathrm{T}_{\mathrm{w}}$ & $1.2 \mathrm{~T}_{\mathrm{w}}$ & $1.5 \mathrm{~T}_{\mathrm{w}}$ \\
\hline
\end{tabular}

$T_{w}$, daily water temperature in the tributary streams coming into the Aguamilpa reservoir. 
also a variation measurement among the simulations that make up the assembly, even including information about extreme conditions such as ENSO events in the study area. The generation of the climatological scenarios for the uncertainty analysis was performed with a very high temporary resolution (a daily resolution). It was necessary to apply advanced statistical methods to stochastically simulate the climatological series. Monte Carlo simulations were used to prove different probability distributions for each variable of interest, producing hundreds of possible results (Kinzig et al., 2003; Zhao et al., 2011). The Monte Carlo simulation consists of generating a time series following a distribution that represents a probability of occurrence (Fig. 3). The key to a successful Monte Carlo simulation is a consistent experiment, generating random samples for precipitation and air temperature. Every Monte Carlo simulation for precipitation and air temperature was modified directly in the input files of the
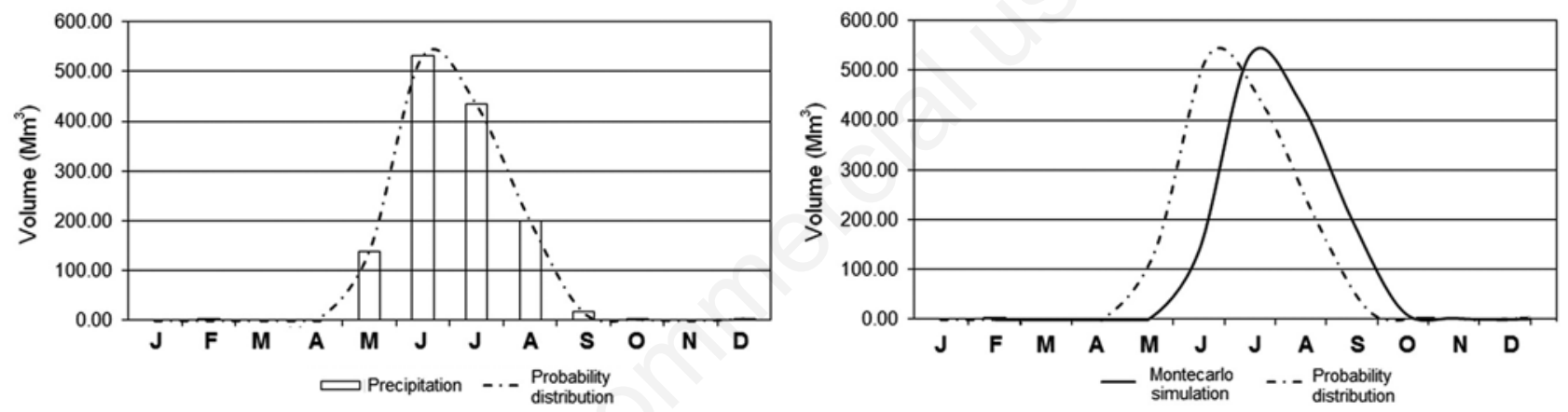

Fig. 3. Precipitation distribution and the generation of probabilistic scenarios in the Aguamilpa reservoir through the application of the Monte Carlo method.

CE-QUAL-W2 model. The water quality model was then evaluated according to the magnitude of the water quality variation.

\section{RESULTS AND DISCUSSION}

\section{Sensitivity analysis}

Fig. 4 shows the parameter effects selected during the sensitivity analysis of the water quality model. The most significant parameters that affect the Aguamilpa reservoir thermic structure are the following: wind sheltering coefficient (WSC), Chezy bottom friction solution (FRICC) and coefficient of bottom heat exchange, in this contribution order. The WSC affected the water temperature profile in the reservoir during the stratification period, modifying the thermocline depth and accelerating the vertical mixing during the cold dry season. This situation may be observed in Fig. 5.
Fig. 4. Sensitivity analysis for selected parameters of the water

quality model.

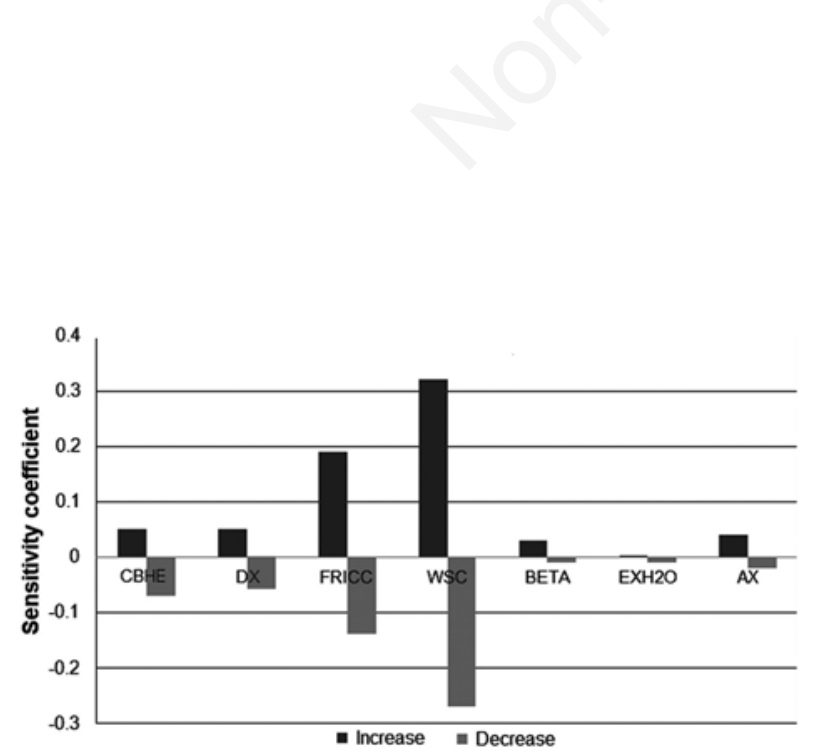

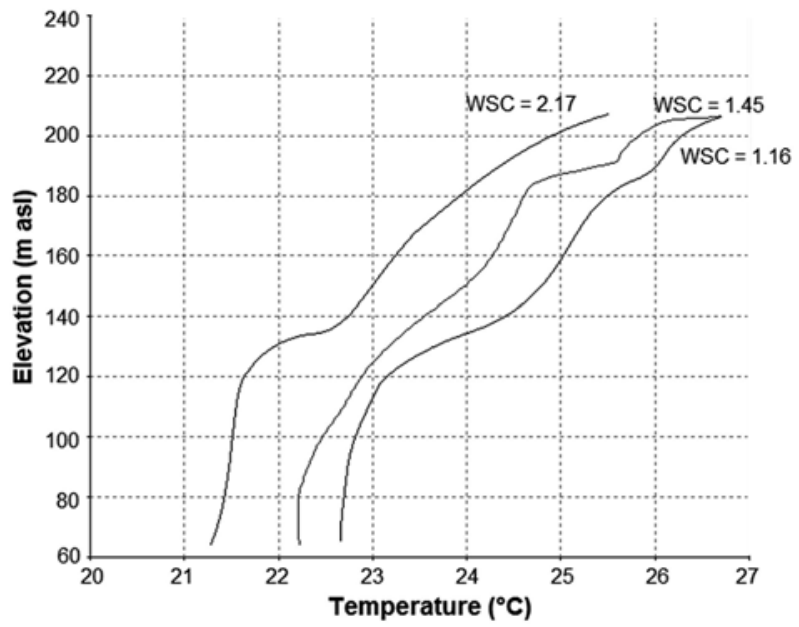

Fig. 5. Wind-sheltering coefficient effect on the thermic profile of the Aguamilpa reservoir water. 
On the other hand, the increase in FRICC values ended up being an additional contribution to the water column heat exchange and to the acceleration of the mixing process. The effect of the coefficient of bottom heat exchange is reflected in a water temperature increase, especially in the reservoir hypolimnion. Ostfeld and Sammons (2005) recognized the same effect for this model parameter and suggested that it may be due to the presence of thermocline. The remaining parameters analyzed, including AX, DX, BETA, and EXH2O, did not show a significant effect on the water temperature. Likewise, it has been demonstrated that the water temperature in the input currents also did not have a significant effect on the thermic structure of the reservoir (Rangel-Peraza et al., 2012). This situation may be associated with the fact that the reservoir mixing process is mainly controlled by the environment temperature, solar radiation, and the wind effect.

A density current was observed in the Aguamilpa reservoir when a decrease in water inflow temperatures occurred. The density of the inflow was more than that of the surface layer; hence, the inflow was distributed to an intermediate layer of similar density. The cold (denser) water was pushed below the warm water, and a small recirculation flow appeared. The zone where the underflow was recirculated was called the plunge point and represents the transition between the turbulent open channel and stratified flows in the reservoir. This plunge point was highly variable in the Aguamilpa reservoir because it depended on water inflow temperature and velocity. According to the results observed in this study, the plunge point in the Aguamilpa reservoir is observed at a distance of 10 km (Fig. 6).

\section{Uncertainty analysis}

An uncertainty analysis was performed as part of the model optimization process. The methodology of uncertainty analysis was based on the Monte Carlo method (Granichin et al., 2014). Some intervals were generated from the historical behavior of climatological variables that define the water quality model, such as rainfall and air temperature. This methodology allowed for testing the probability distribution behavior of air temperature and rainfall. These characteristics were modified in the input profile of the water quality model, and a model run was carried out for each generated distribution, producing a set of results. According to the simulation results, the confidence intervals were calculated and then analyzed based on the probability that these results would occur. Figs. 7 and 8 show the direct rainfall volume and the minimum and maximum air temperature behavior in the Aguamilpa reservoir, respectively. In these figures, it is possible to identify that the intervals within these values are found in the uncertainty analysis carried out in this study. The confidence interval depicts the interval values that carry a cer- tain probability of finding the measurements observed. This confidence interval is important because it quantifies the influence of the uncertainty on the response variable; in this way, the reliability of the water quality model pre-

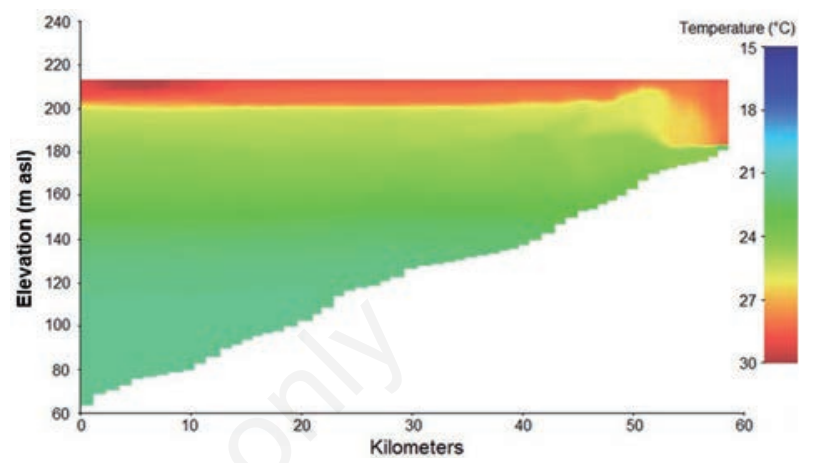

Fig. 6. Presence of density current in Aguamilpa reservoir.

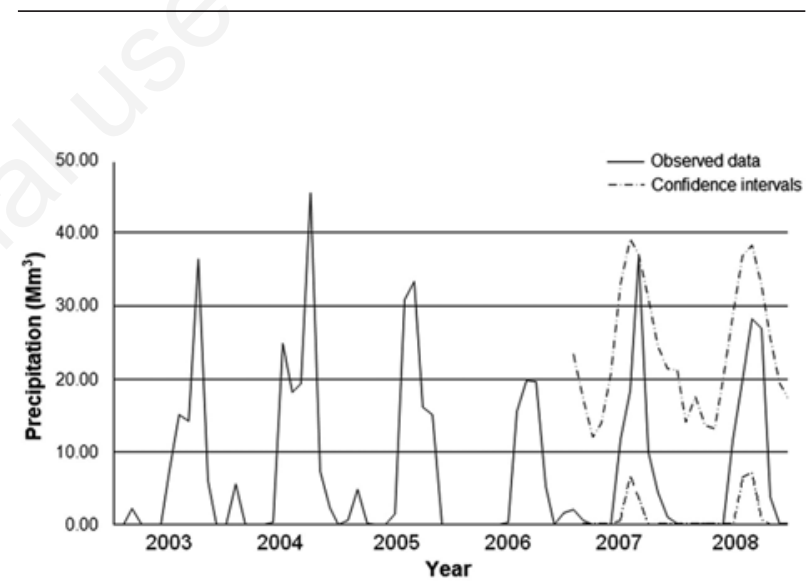

Fig. 7. Direct precipitation volume observed in the Aguamilpa reservoir and the confidence intervals calculated during the simulation period.

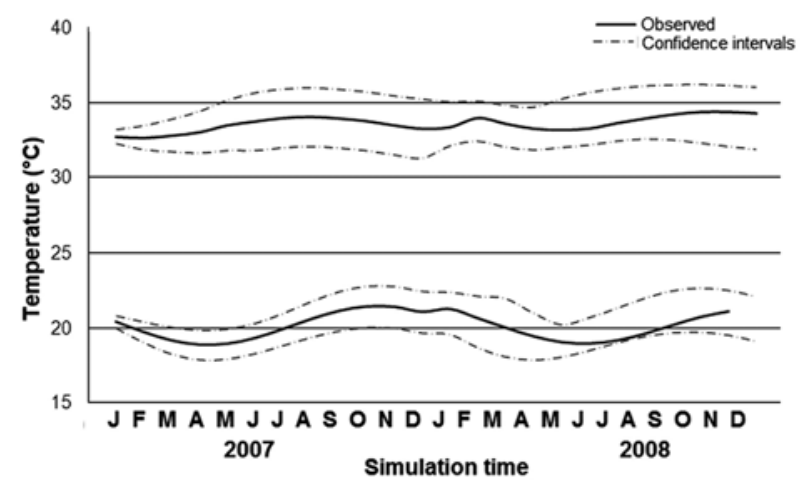

Fig. 8. Minimum and maximum air temperature behavior, emphasizing the confidence intervals calculated in the Monte Carlo simulation. 
dictions can be evaluated (Coleman and Steele, 2009). From Fig. 7, it is observed that the daily rainfall does not meet a Gauss symmetric distribution. Nevertheless, when a behavior modification is performed for this variable, including it as an accumulated precipitation, it is possible to adjust the behavior of this variable to meet a normal distribution. Afterwards, precipitation values generated during the Monte Carlo simulations were used as input data in the CE-QUAL-W2 model. According to the results shown in Fig. 8, the maximum air temperature used for uncertainty analysis was $34.35^{\circ} \mathrm{C}$, with a confidence interval from $33.19^{\circ} \mathrm{C}$ to $36.51^{\circ} \mathrm{C}$. The minimum air temperature generated in the Monte Carlo simulation was $18.86^{\circ} \mathrm{C}$, with a confidence interval from $16.73^{\circ} \mathrm{C}$ to $21^{\circ} \mathrm{C}$. Based on the air temperatures generated, it can be argued that the water quality simulation carried out within these limits could be considered as a climate change scenario in the Aguamilpa reservoir according to the ranges established by Martinez-Arroyo et al. (2011). These authors have predicted an increase of $2^{\circ} \mathrm{C}$ in the air temperature of the study area for the year 2050 . This prediction indicates that the results of the uncertainty analysis carried out in this study represent a contribution to the development of predictive models for better water resource management in a reservoir.

Fig. 9 depicts a typical problem that occurs during the uncertainty analysis of water quality modelling. Once different scenarios were generated for precipitation, it was necessary to correct the reservoir water balance to consider the effects of this variable on the water quality model. A propagation of precipitation uncertainty in the water balance model was observed. This problem is well known as an initial value problem in which the results, in a deterministic context, are inclusive over time. Under this framework reference, a better initial condition results in a superior prediction (Refsgaard et al., 2007). The simulations of the water quality model cannot be extended for a long time before the level drops below the threshold that makes them useful. Simulations carried out with uncertainty propagation of continuous variables amplify the initial condition errors. Even when the simulations start with similar initial conditions, the level of uncertainty in the continuous variable determines the difference in the model response and may even cause highly contrasting results.

To counteract the effect described above, it was nec- essary to group the results of the Monte Carlo simulation. This process is called statistical block and constitutes a classification of the results as a function of the observed average in the time series generated (Vasquez and Whiting, 2005). An analysis of variance was performed for the 500 scenarios generated for both variables (precipitation and air temperature), and the results were classified into 4 homogeneous groups, which are presented in Tab. 3 . The interpretation of the uncertainty analysis results is a complex task because the water quality variables exhibit a particular behavior for each simulation performed. In this sense, the statistical block favoured the explanation and presentation of these results. Therefore, it was essential to assume that the response of the water quality model was similar for each of the different grouped scenarios. This assumption can be made because the distribution of meteorological variables does not present significant differences within groups, according to ANOVA. Fig. 10 shows the behavior of the surface water temperature of the Aguamilpa reservoir under the different stochastic scenarios generated compared with the real behavior registered. The results indicate that a future decrease in air temperature (Scenario 1) would have a positive impact on the reservoir because the difference between the surface and bottom water temperature is small, which in turn would be beneficial for breaking down the thermocline. Therefore, a full mixed reservoir could be observed during the cold dry season.

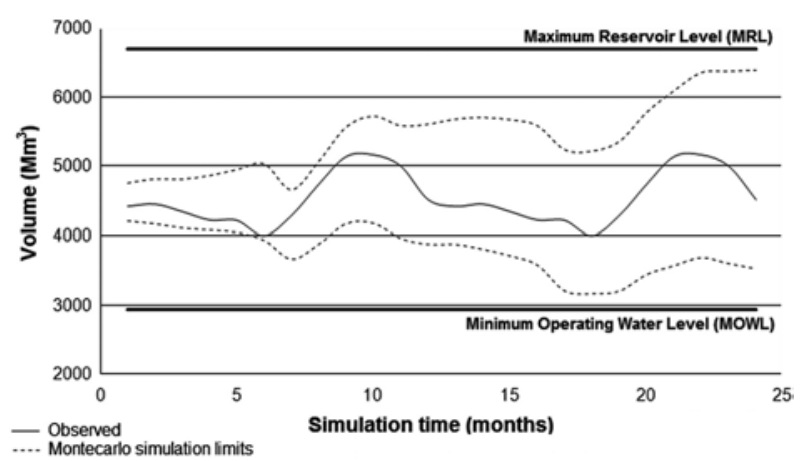

Fig. 9. Precipitation uncertainty propagation observed in volume stored in the Aguamilpa reservoir.

Tab. 3. Proposed scenarios for water quality model uncertainty analysis in the Aguamilpa reservoir.

\begin{tabular}{ll} 
Name & Characteristics \\
Scenario 1 & Mean air temperature significantly lower (air temperature average less than $24.3^{\circ} \mathrm{C}$ ) \\
Scenario 2 & Accumulated mean precipitation significantly smaller (mean rainfall less than $31.4 \mathrm{~mm} \mathrm{month}^{-1}$ ) \\
\hline Scenario 3 & Mean air temperature significantly greater (air temperature greater than $29.1^{\circ} \mathrm{C}$ ) \\
Scenario 4 & Accumulated mean precipitation significantly higher (mean rainfall greater than $125.4 \mathrm{~mm} \mathrm{month}^{-1}$ ) \\
\hline
\end{tabular}


A completely opposite behavior was observed under a water level decrease (Scenario 2). When rainfall is significantly less, a stronger stratification was observed during the warm dry season. A surface water temperature of $34.9^{\circ} \mathrm{C}$ was achieved, while thermal conditions in deeper waters of Aguamilpa were $23^{\circ} \mathrm{C}$. This situation occurred because the lower the amount of water, the lower the surface area in the reservoir. Therefore, despite the solar radiation conditions and air temperature in the region being the same, precipitation reduction caused an increase in the surface water temperature and in the water lost due to evaporation.

On the other hand, an increase in the air temperature (Scenario 3) would cause an increase in the surface temperature of the reservoir, a situation that would consolidate the present thermocline (Fig. 11). The results showed a significant difference between surface water temperatures of the different scenarios studied. However, the water temperature was similar for all scenarios below the thermocline. Finally, the results showed less uncertainty for output variables of the water quality model due to an increase in water level of the Aguamilpa reservoir (Scenario 4).

According to the aforementioned scenarios, uncertainty analysis quantified the water quality effect of atypical weather events on a regional scale, such as ENSO events. According to the rainfall data used for scenario simulations (CONAGUA, 2008), significantly less precipitation was observed during 2006 in the study area. This situation may be associated with El Niño Southern Oscillation, which was registered in Mexico for this year (Cerano-Paredes et al., 2010). Due to these data being included during uncertainty analysis, water quality simulations included the effect of the cold phase of ENSO in the Aguamilpa reservoir.

A similar analysis can be performed for the warm phase of ENSO. The historical rainfall behavior showed

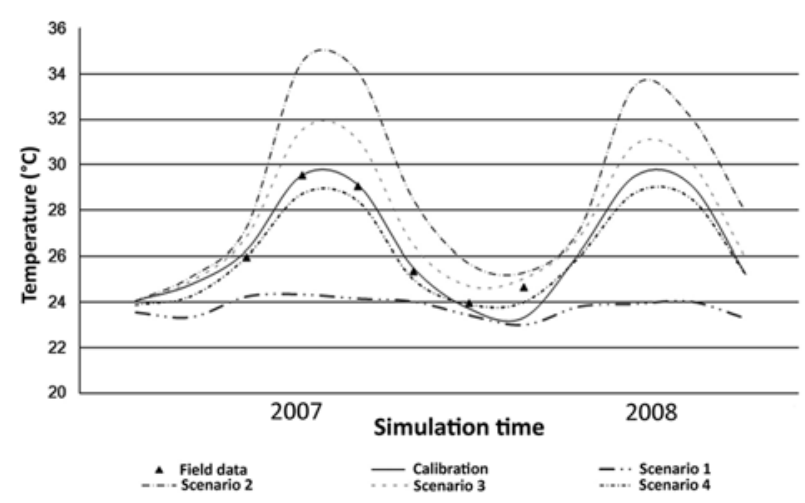

Fig. 10. Surface water temperature behavior of Aguamilpa reservoir under different scenarios. convective storms and historical maximum precipitation volumes during the rainy season in 2004 (CONAGUA, 2008). The slight difference between the upper confidence bound used in the uncertainty analysis and rainfall behavior observed during 2004 may explain the low variability observed in water quality simulations for Scenario 4. Hence, uncertainty analysis of the water quality modelling reflected the effects of the warm phase of ENSO. In the case of dissolved oxygen, the observed behavior for this parameter is similar to that registered for water temperature. In scenarios in which a thermal stratification was observed, a difference in the concentrations of dissolved oxygen from the surface to the bottom of the reservoir was also presented, with the presence of an oxycline.

According to the results obtained, it is recognized that the hydrodynamic behavior of the reservoir determines the behavior of the variables of water quality. A surface temperature increase in the reservoir (Scenarios 1 and 2) would decrease the dissolved oxygen concentration. This situation can be attributed to the decline of the solubility of this gas in the water due to temperature. This phenomenon represented the main difference between the dissolved oxygen observed and simulations performed under different scenarios. The global uncertainty analysis of the water quality model for different scenarios of dissolved oxygen concentrations is shown in Tab. 4.

The interpretation of the results for the dissolved oxygen was carried out via global uncertainty analysis. The uncertainty for the dissolved oxygen was evaluated by calculating the absolute mean error (AME) and root mean square error (RMSE). RMSE and AME are suggested as general tests to evaluate the correspondence, or the degree of adjustment, between the values predicted initially by the model and those observed in the different scenarios. RMSE and AME are calculated using equations 2 and 3, respectively:

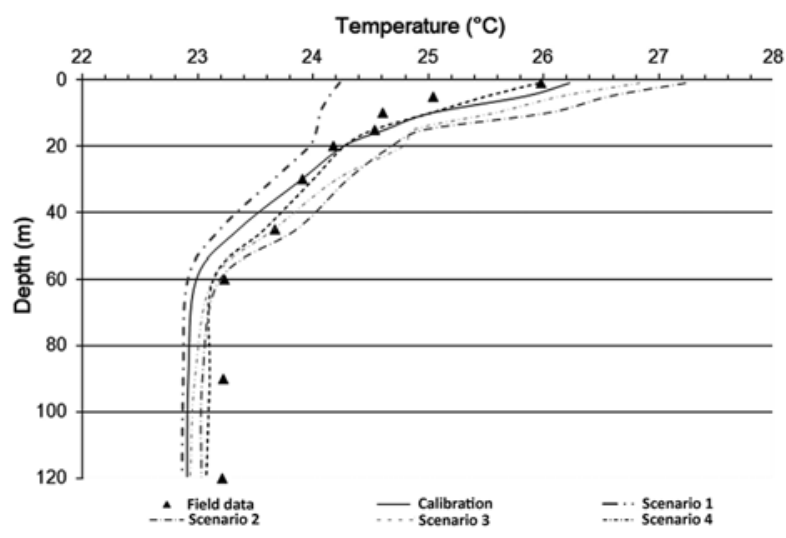

Fig. 11. Behavior of water column temperature of Aguamilpa reservoir during June for the different proposed scenarios. 


$$
\begin{aligned}
& R S M E=\sqrt{\frac{\sum_{I=1}^{N}\left(X_{i, o b s}-X_{i, i n c}\right)^{2}}{N}} \\
& A M E=\frac{\sum_{I=1}^{N}\left|X_{i, o b s}-X_{i, i n c}\right|}{N}
\end{aligned}
$$

where

$\mathrm{N}=$ number of simulations;

$\mathrm{X}_{\mathrm{i}, \mathrm{obs}}=$ initial value of the $\mathrm{i}$-th observation of dissolved oxygen $(\mathrm{X})$;

$\mathrm{X}_{\mathrm{i}, \mathrm{inc}}=$ uncertainty analysis value of the $\mathrm{i}$-th observation of dissolved oxygen $(\mathrm{X})$.

The error is greater according to the difference between the calibrated value and the value obtained in the uncertainty analysis. A value of zero indicates a null uncertainty.

It is observed in Tab. 4 that a greater uncertainty was recorded for Scenarios 1 and 2, corresponding to the behavior observed for water column temperature. Similarly, Scenario 4 presented the lowest uncertainty for dissolved oxygen, which confirms the assumption that water temperature is a crucial variable in the hydrodynamics of the Aguamilpa reservoir. Finally, Fig. 12 showed that the behavior of the total dissolved solids varied significantly regarding the input streams (precipitation). This situation could seriously affect the silting process at the Aguamilpa reservoir. However, due to total dissolved solids (TDS) being a conservative parameter, its concentration did not present a significant difference during the uncertainty propagation in air temperature.

\section{CONCLUSIONS}

In this research, parametric optimization of the water quality model for the Aguamilpa reservoir was carried out through sensitivity and uncertainty analysis in a modular context. This optimization was carried out by modifying the hydrological and climatological observed parameters, which intervene in reservoir simulations over time. The combination of the modular simulations has assisted in quantifying the effect (sensitivity) and the error (uncertainty) associated with the variation of the water quality model parameters.
The main idea of the sensitivity analysis was to identify the most important weaknesses of the water quality model. This analysis identified that WSC, FRICC and CBHE are the parameters of the CE-QUAL-W2 model, having the most influence on the temperature and dissolved oxygen behavior. In this sense, it is suggested that in future works related to water quality modelling in tropical reservoirs, efforts should be focused on the calibration of these parameters. This could significantly reduce the simulation time during the calibration process. Uncertainty analysis carried out in the present study was based on the simulation of the probability density functions for the precipitation and air temperature in the area of study. These simulations have created an arbitrary number of potential real-world scenarios for both parameters. Frequency distributions were adapted to the water quality model, introducing a new concept of parametric dynamism. With this new concept, hydrological and meteorological scenarios and water quality information of the Aguamilpa reservoir were generated consistently. Therefore, the results of these simulations allowed for better knowledge of the behavior of this ecosystem in present and future climatic conditions. The uncertainty analysis showed changes that can be observed in the hydrodynamic and water quality characteristics of the reservoir. However, these results must be viewed with caution given the limitations of the model. In this way, the results displayed simply represent the possible scenarios expected

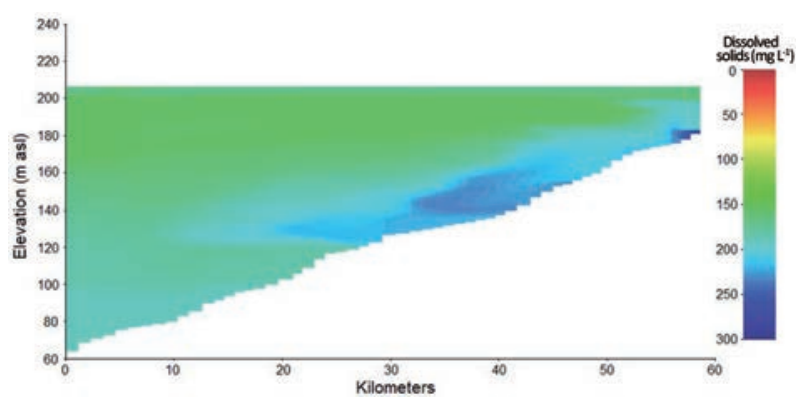

Fig. 12. Total dissolved solids behavior for Scenario 4.

Tab. 4. Absolute Mean Error (AME) and Root Mean Square Error (RMSE) of the dissolved oxygen concentrations under the different scenarios of simulation.

\begin{tabular}{lcccc} 
& Simulated & Scenario 1 & Scenario 2 & Scenario 3 \\
Simulated & & $0.481^{*}$ & $0.615^{*}$ & $0.299^{*}$ \\
Scenario 1 & $0.328^{* *}$ & & $1.096^{*}$ & $0.201^{*}$ \\
\hline Scenario 2 & $0.837^{* *}$ & $1.113^{* *}$ & $0.493^{*}$ & $0.915^{*}$ \\
Scenario 3 & $0.125^{* *}$ & $0.064^{* *}$ & $0.497^{* *}$ \\
\hline Scenario 4 & $0.033^{* *}$ & $0.430^{* *}$ & $0.651^{* *}$ & $0.346^{*}$ \\
\hline
\end{tabular}

*Absolute Mean Error; **Root Mean Square Error. 
for the reservoir, which include the possible effect of climate change and/or the effect of ENSO events on the reservoir but do not represent accurate predictions.

Finally, the bases for future development of a platform for modelling were established to perform reliable simulations of the water quality in the Aguamilpa reservoir in real-time using a continuous update of the meteorological conditions and discharge. The methodology used in the present research is suggested as reliable for application in the development of water quality models for other large reservoirs located in the Rio Grande de Santiago watershed, such as the El Zapotillo, La Yesca, and El Cajon reservoirs.

\section{ACKNOWLEDGMENTS}

The authors acknowledge the National Council of Science and Technology in Mexico (CONACYT) for supporting this research work in the call for funds of basic science of 2006.

\section{REFERENCES}

Afshar A, Saadatpour M, 2009. Reservoir eutrophication modeling, sensitivity analysis, and assessment: application to Karkheh Reservoir, Iran. Environ. Eng. Sci. 26:1227-1238.

Aquaveo, 2010. Watershed Modeling System. Available from: http://wmstutorials.aquaveo.com/Tutor84_Vol_VI.pdf

Arnold JG, Srinivasan R, Muttiah RS, Williams JR, 1998. Large area hydrologic modeling and assessment. Part 1, Model development. J. Am. Water Resour. Ass. 34:73-89.

Brohan P, Kennedy JJ, Harris I, Tett SFB, Jones PD, 2006. Uncertainty estimates in regional and global observed temperature changes: a new data set from 1850. J. Geophys. Res. 111:27.

Caers J, Hoffman T, 2006. The probability perturbation method: a new look at Bayesian Inverse Modeling. Math. Geol. 38:81-100.

Cerano-Paredes J, Villanueva-Diaz J, Arreola-Ávila JG, Sánchez-Cohen I, Valdez-Cepeda RD, García-Herrera G, 2010. [Reconstrucción de 350 años de precipitación para el suroeste de Chihuahua, México].[Article in Spanish]. Madera y Bosques 15:27-44.

CFE, 1991. [Proyecto hidroelectrico Aguamilpa].[in Spanish]. General Information of Aguamilpa Project. Mexico: 47 pp.

Cole TM, Wells SA, 2005. CE-QUAL-W2: A two-dimensional, laterally averaged, Hydrodynamic and Water Quality Model, Version 3.2. Rep. No. Instruction Report EL-03-1. US Army Engineering and Research Development Center, Vicksburg: $681 \mathrm{pp}$.

Coleman HW, Steele WG, 2009. Experimentation, validation, and uncertainty analysis for engineers. J. Wiley \& Sons: 336 pp.

CONAGUA, 2008. [Datos hidrológicos y climatológicos en la cuenca Santiago-Aguamilpa].[Report in Spanish]. Comisión Nacional del Agua, Subdirección General Técnica, Gerencia de Saneamiento y Calidad del Agua: 102 pp.

de Anda J, Rangel-Peraza JG, Obregon O, Nelson J, Williams GP, Jarquín-Javier Y, Miller J, Rode M, 2012. The use of digital elevation models (DEMs) for bathymetry development in large tropical reservoirs. In: P. Blondel (ed.), Bathymetry and its applications. InTech.
Estrada F, Gay C, Conde C, 2008. [Un nuevo enfoque para la construcción de escenarios probabilísiticos de cambio climático].[Article in Spanish]. Proceedings VI Congr. of Spanish Climate Association, Tarragona, Spain.

Gay C, Estrada F, Sánchez A, 2008. Global and hemispheric temperatures revisited. Climatic Change 94:333-349.

Granichin O, Volkovich Z, Toledano-Kitai D, 2014. Randomized algorithms in automatic control and data mining. Springer: $247 \mathrm{pp}$.

Hutson JL, Wagenet RJ, 1991. Simulating nitrogen dynamics in soils using a deterministic model. Soil Use Manage. 7:74-78.

INEGI, 2011. [Sistema de descarga del continuo de elevaciones en la República Mexicana].[Report in Spanish]. Available from: http://mapserver.inegi.org.mx/DescargaMDEWeb/?s= geo\&c $=977$.

IPCC, 2014. Climate change 2014: impacts, adaptation, and vulnerability. Part A: global and sectoral aspects. Contribution of Working Group II to the Fifth Assessment Report of the Intergovernmental Panel on Climate Change. Cambridge University Press, Cambridge: 1132 pp.

Kinzig A, Starrett D, Arrow K, Aniyar S, Bolin B, Dasgupta P, Ehrlich P, Folke C, Hanemann M, Heal G, Hoel M, Jansson A, Jansso BO, Kautsky N, Levin S, Lubchenco J, Maler KG, Pacala SW, Schneider SH, Siniscalco D, Walker B, 2003. Coping with uncertainty: a call for a new science - Policy Forum. Ambio 32:330-335.

Lienert F, Doblas-Reyes FJ, 2013. Decadal prediction of interannual tropical and North Pacific sea surface temperature. J. Geophys. Res.-Atmos. 118:5913-5922.

Lindenschmidt KE, 2006. The effect of complexity on parameter sensitivity and model uncertainty in river water quality modelling. Ecol. Modell. 190:72-86.

Martinez-Arroyo A, Manzanilla-Naim S, Zavala-Hidalgo J, 2011. Vulnerability to climate change of marine and coastal fisheries in Mexico. Atmosfera 24:103-123.

Omlin M, Brun R, Reitchert P, 2000. Biogeochemical model of Lake Zürich model: sensitivity, indentifiability and uncertainty analysis. Ecol. Modell. 141:105-123.

Oracle, 2013. Netbeans IDE enterprise pack. Available from: https://netbeans.org/downloads/

Ostfeld A, Salomons S, 2005. A hybrid genetic - instance based learning algorithm for CE-QUAL-W2 calibration. J. Hydrol. 310:122-142.

Railsback SF, Grimm V, 2012. Agent-based and individualbased modeling. Princeton University Press: 329 p.

Rangel-Peraza JG, de Anda J, González-Farías FA, Erickson DE, 2009. Statistical assessment of water quality seasonality in large tropical reservoirs. Lakes Reserv. Res Manage. 14:315-323.

Rangel-Peraza JG, Obregon O, Nelson J, Williams GP, de Anda J, González-Farías FA, Miller J, 2012. Modelling approach for characterizing thermal stratification and assessing water quality for a large tropical reservoir Lakes Reserv. Res Manage. 17:119-129.

Rangel-Peraza JG, Ortiz-Jimenez MA, 2012. [Balance hidrico en la presa de Aguamilpa]. In: J. de Anda, F.A. Gonzalez-Farias (eds), [Calidad del agua en la Presa Aguamilpa].[Book in Spanish]. Guadalajara, Mexico.

Refsgaard JC, van der Sluijs JP, Hojberg AL, Vanrolleghem PA, 2007. Uncertainty in the environmental modeling process. 
A framework and guidance. Environ. Modell. Softw. 22:1543-1556.

Reichert P, 1994. AQUASIM - A tool for simulation and data analysis of aquatic systems. Water Sci. Technol. 30:21-30.

Reichert P, 2004. UNCSIM - A computer programme for statistical inference and sensitivity, identifiability, and uncertainty analysis, pp. 51-55. In: J.M.F. Teixeira and A.E. CarvalhoBrito (eds.). Proceedings of the European Simulation and Modelling Conference, Porto, Portugal.

Rode M, Arhonditsis G, Balin D, Kebede T, Krysanova V, van
Griensven A, van der Zee S, 2010. New challenges in integrated water quality modelling. Hydrol. Process. 24: 3447-3461.

Vasquez VR, Whiting WB, 2005. Accounting for both random errors and systematic errors in uncertainty propagation analysis of computer models involving experimental measurements with Monte Carlo methods. Risk Anal. 25:669-1681.

Zhao X, Shen ZY, Xiong M, Qi J, 2011. Key uncertainty sources analysis of water quality model using the first order error method. Int. J. Environ. Sci. Tech. 8:137-148. 